\title{
The Analysis of the Practical Significance of Design Philosophies in Zhuangzi
}

\author{
Huang Jieming \\ School of Fashion, Wuhan Textile University, Wuhan, 430073, China. \\ email: 826028808@qq.com
}

Keywords: Zhuangzi, Practical Significance, Design Philosophies

\begin{abstract}
The thoughts of Zhuangzi are mainly reflected in the book Zhuangzi. As the chapter "Under the Heaven" wrote, "People were lost to the pleasures of the material wealth and could not be argued with or reasoned with." Zhuangzi said he himself "developed speeches with daily random words, respected quotations from sages and illustrated with fables." The marvelous and elusive words of Zhuangzi express his reflections on life and politics. His articles are full of philosophic thoughts. "Reveal the philosophy of man and objects" is the essence of Chinese ancient wisdom. Because Zhuangzi was concerned about social conventions and reality, some views and elaborations about artifacts and design can also be found in his thoughts, which are important components of Chinese traditional design philosophies. This paper briefly analyzes the important design philosophies implied in Zhuangzi.
\end{abstract}

\section{Introduction}

Zhuangzi's philosophy is the view on life, universe and values within the whole view system of nature, including the consumption view, the definition on worships and delights, the description of ideal personality, and the standard of choosing artifacts etc, which forms a system of design philosophy. A unique view of nature and the relation between man and nature are shown in Zhuangzi. Nature is described as a vital life entity by Zhuangzi, and man is also a part of it, which is as natural as everything. [1] The relation between nature and man is harmonious. Through fables, Zhuangzi implies the harmonious relation between man and objects as well as nature.

\section{Theory of nature and man in design: lose oneself in pursuit of something and match man's natural disposition with the natural disposition of nature}

\section{A. Lose oneself in pursuit of something}

Zhuangzi told a story in the chapter "The Heaven and the Earth", which is a fable about an old gardener who would fetch water with a jar to water the fields rather than use a well-sweep:

After his travel to the state of Chu in the south, Zigong returned to the state of Jin. [2] When he was passing by the southern bank of the Hanshui River, he saw an old man working in his vegetable garden. From a tunnel that reached the bottom of the well, the old man was fetching water with a jar to water the fields. He had been working hard at it but by no means efficiently. Zigong said, "There is a kind of machine with which you can water a hundred plots a day. You don't have to work so hard but will work much more efficiently. Don't you want to have one?”

The old gardener looked up and said, "How does it work?"

Zigong said, "The machine is made of wood that is heavy in the rear and light in the front. It draws water like pouring, as if the water was boiling over. It is called a well-sweep."

His face red with anger, the gardener grinned and said, "I have learned from my teacher that a man who employs an ingenious machine must do ingenious deeds and that a man who does ingenious deeds must have an ingenious mind. A man with an ingenious mind will not be pure and simple; a man without a pure and simple mind will have an unrestful spirit; a man with an unrestful spirit will not attain Tao. I don't use a well-sweep not because I don't know that it works well, but because I feel it a shame to use it.” 
Abashed, Zigong bent his head and made no reply.

In this fable, Zhuangzi used the old gardener's words to point out the antagonism between man and objects. In his opinion, "a man who employs an ingenious machine must do ingenious deeds and that a man who does ingenious deeds must have an ingenious mind." With an ingenious mind, a man will not be "natural" and "simple" any more.

Many Zhuangzi’s comments are against indulging oneself in objects. For example, in the chapter "Declining the Throne”, Zhuangzi wrote “Isn’t it lamentable that most worldly gentlemen have disregarded their natural disposition and sacrificed their lives in pursuit for material possessions?" [3] In the chapter "Cultivation of the Inborn Nature", he wrote "Therefore, as the saying goes, "Those who lose themselves in pursuit of something and those who lose their inborn nature under the influence of worldliness are men who put the cart before the horse.'” All of these can be summarized as Zhuangzi's thought that one's mind will be harmed with the objects' influence. A man with an ingenious mind will have an unrestful spirit and will not attain Tao. Only being not disturbed by external affairs can one keeps single-minded.

The thoughts about losing oneself in pursuit of something and those who lose their inborn nature under the influence of worldliness are very forward-looking.

In the late 1920s, Heidegger, through the questioning of "objects" and technology, altered the traditional relationship between man and things. [4] In the western booming, Heidegger made the argument of ontological from the origin of the technology, the nature of technology and the limitations of technology, having foreseen the consequences brought by the unlimited development of technology is man's sense of loss and alienation in full scale. Afterwards, a group of thinkers who constantly criticized the negative impact on people's life brought by modern technology and industrialization emerged. [5] They realized in different extent that the expansion of technology and the industrialization of society make people extremely rational, forget the existence of their own in the hush to recognize and reconstruct the world. A kind of alienated relationship generates between man and things. The excessive reliance on machinery and technology has led to people's enslavement and deconstruction by the tools at hand.

Objecting to lose oneself in pursuit of something, pursuing the liberation of nature and individuality both are the philosophy that Zhuangzi and Heidegger once claimed.

\section{B. Match man's natural disposition with the natural disposition of nature}

In the chapter "A Thorough Understanding of Life”, Zhuangzi told a story about "Qing the Carpenter carved a piece of wood to make a bell frame", which illustrates his philosophy of holding oneself aloof from the world, matching man's natural disposition with the natural disposition of nature:

Qing the Carpenter carved a piece of wood to make a bell frame. When the bell frame was completed, all those who saw it were astonished as though it were a supernatural accomplishment. Upon seeing it, the Marquis of Lu asked Qing, saying, "What is the mystery in your art?"

Qing the Carpenter said, "I am but a carpenter, how can I have any mystery in art! However, I have one thing to say. When I was about to work on the frame, I dared not have my energy distracted. I must fast to concentrate my mind on it. After three days of fasting, I no longer had any thought of reward or gains; after five days of fasting, I no longer had any thought of comments or skills; after seven days of fasting, I no longer had any thought of my limbs or my physical form. At that time, with no thought of royal court, I was concentrated on my craftsmanship and I dispelled myself from all thoughts of the outside of the world. [6] Then I entered a mountain forest to observe the natural qualities of the wood. When I found a tree for the right shape, I saw the bell frame in my mind's eye and set my hand to the job. If not, I just let it go. In this way, I matched my natural disposition with the natural disposition of the tree. That is probably why the bell frame looks as though it were a supernatural accomplishment.”

The story tells us that the secret of making a bell frame which looks as though it were a supernatural accomplishment is "matching man's natural disposition with the natural disposition of nature". In order to make a bell frame, the carpenter firstly "fasts to concentrate his mind on it", 
abandons the thoughts of reward or gains, comments or skills until he even forgets his own existence, then he can enter a mountain forest to observe the natural qualities of the wood. He becomes the bond between a carpenter who is a man in nature and a man who is naturalized. Only having gone through the process of forgetting reward or gains, worldliness and his own existence can the carpenter clear his mind, come back to the simple and pure state and "found a tree for the right shape, when the bell frame was completed, all those who saw it were astonished as though it were a supernatural accomplishment”.

The process of craftsman creating the drumstick gives a clear demonstration of Zhuangzi's view of nature - "the harmony between human and nature", that is to say, the ordinary people intrigued by fame and fortune are incapable of dialogue with nature. The state of not being slaved by materials but being united with nature can only be achieved when social utilitarianism is eliminated and the "pure nature" realized, which means the obliviousness of materials and oneself to unify the pure natural mind with objective principles in nature.

Yet the "nature" that Zhuangzi takes as a beauty is not the so-called "Nature". The word "nature" in "the harmony between human and nature" sometimes is also called "natural instinct" by Zhuangzi, who believes that beauty means all things must comply with their own natural instincts; if the laws of things' development are violated, then nature is lost, so is beauty. Therefore he takes a firm stand on the idea of respecting the natural laws.

\section{Design based on the laws of nature}

Art should be based on and regulated by the laws of nature. [7] This is Zhuangzi's basic idea about what we call art design today, giving significant inspiration to future generations.During the process of creation, natural factors are ought to be fully considered in a way that maintains vitality within the nature's limits;besides, after the creation of new things, humans must integrate with the fresh environment around. The major points where later designers should pay more attention to are the continuing development between human and nature as well as the harmony between man-made objects and nature.

The urban design in Holland represents a classic design case on the basis of the relationship between human and nature. The urban environmental design in Holland is mainly conditional upon its unique geographical factor. Since most of its territory is below sea level, huge levees must be built in rural areas to prevent floods and tides, canals and bridges are main transportation mediums in cities, and the design of railways, ports, airports, currency and underground railway system all feature high unity and functionality. Take the underground railway system in Amsterdam as an example, it boasts not only safety, cosiness and high efficiency, but also unification and systematization in design that clearly conveys information.

If Holland's urban design is said to follow the laws of nature and deliver the philosophy of maintaining harmony between natural environments and humans, then the new Suzhou Museum designed by leoh Ming Pei can be called the embodiment of environmental "naturalization", reflecting the important role of the "artificial”nature in environmental design.

In the design of the new museum with the charm south of the Yangze, leoh Ming Pei puts to use a large number of traditional Chinese architectural elements. The entire building complex in a tone of grey echoes traditional dwellings with its texture of ancient city, representing the primitive charm of Suzhou City with "white walls and black tiles". The inspiration for the exterior courtyard scene design at the entrance of the new museum comes from the artistic conception of the landscape painting of $\mathrm{Mi} \mathrm{Fu}$, a great Northern Song Dynasty painter. Actually, the scene itself resembles a long scroll painting of landscape with the southern wall of the Humble Administrator's Garden as a piece of drawing paper, in which a stack of Mount Tai stones are piled up in the courtyard pool. In addition, Pei "let the light do the design"-the geometric deconstruction of the roof makes it possible that the scattered sunlight can easily slant through the window, enriching the interior space of the building with light and shadow effects. Pei's employment of mountain rocks, flowing water, lighting and garden arts constitute a harmonious picture of architecture and nature. 


\section{Design based on moral value: worships, delights and consumption}

What are people's “worships and delights”? Is there a ceiling for desire? Human beings have always had subjective limitations on the cognition of their own nature since ancient times.

Confucius believes that the virtuous should abide by the ritual-musical civilization that conforms to their status. Guan Zhong also affirms the rationality for the rich to use luxurious crafts. He said: "If the rich don't purchase, the craftsmen will lose sources of livelihoods.” Zhuangzi's idea bears something in common with Laozi and Mozi's ideas, because they all hold the opinion that sounds, colors, goods and profits cause human beings to lose their pure nature and lead to social turmoil. Zhuangzi thinks that people's impulse to quench their desires is dangerous. Once people pursue extravagant life, they would inevitably suffer a lot.

\section{A. The limitations of "worships and delights" and the polarization of "consumption"}

Zhuangzi reveals the secular values of worships and delights in the beginning of his article The Ultimate Happiness: the honorable people are those who are rich, powerful, longevous and virtuous. People take delight in physical comfort, delicious food, luxurious clothing, rich colors and euphony; while they suffer from the lack of them. Such unwise thoughts are harmful to their health. The rich people work hard to accumulate a large amount of money, yet they can't spend it all, which neglects their health. The powerful people puzzle over how to keep their high positions and salaries day and night, which overlooks their well-being. However, Zhuangzi puts forward that : "I take delight in letting things take their own course." (The Ultimate Happiness) He believes that no matter how luxurious life one lives, if he couldn't get spiritual freedom, then he is fettered by something, thus such a life is unattractive. Zhuangzi is an advocate for spiritual freedom, and he mentioned in Yang Sheng Zhu that: "Pheasants would rather live in the water side, walking ten steps to eat and a hundred steps to drink than live in cages. Only when one is unfettered can he attain spiritual freedom and joy.”

Zhuangzi adds spiritual demands of people to social life evaluation and self demands, negating the demands of sensorial life centering on materialism and the idea that material comfort is the evaluation standard of life. In the Period of Warring States, which was underdeveloped in science and technology, Zhuangzi had realized that human nature would gradually lose the ability to make right judgement with the improvement of the material standard of living, which finally made people lose themselves in the materialistic environment.

People's consumption is promoted by the diversification of economy and development of productivity. However, due to the overemphasizing of consumption and the role of domestic demand to driving economic growth, it leans over backwards that giving rise to morbid consumption behavior and extravagance. Not only the rich live in luxury, but also the poor struggle in vain consumption. People's demand for consumption morph into completely material desires and satisfaction of lust. These consumption behavior and mental demands were treated with contempt by Zhuangzi and repelled him at that period.

\section{B. Practical significance of design morality}

The worship and favorite value of Zhuangzi, reflecting in product design, refers to the product function of arousing spiritual pleasure.

Firstly, the appearance design of the form and color of the product, and the overall and partial design should meet the demands of human's visual sense. In order to achieve this goal, designers usually use metaphorical and symoblic languages in form design, such as bionics design, architectural style product design. As to color, designers will put two influential factors in to consideration. In the first place, the demands for color is located based on the estimated features of the age range, purchasing power, cultural gradation and other elements related to the comsumers. In the second place, the key element of choosing the color of the product is its usage. For instance, the cookers design of IKEA will take the kitchen environment into full consideration, and using relative light cool tone and moderate bright tone, in order to balance people's anxiety in busy cooking. 
Secondly, in the process of product using, it should interact with people harmoniously and provide mental pleasure with users. Draw on the ideas of worldly worship and favorite values by Zhuangzi, product design will not provide people with real spiritual pleasure with simple addition design on sense of sight, touch and other feelings. On the contrary, it will impede the free development of spirit. For instance, the 'over-designing' nowadays in house decoration industry adds a large amount of ornaments to the original simple demands. The current interior decoration pay more attention on commercial aesthetic demand. Based on customers' psychology and cater to their pleasure, the decoration company on one hand ask for high construction costs, on the other hand satisfy the customers' vanity with over-spending decoration project. This is also a kind of worship and favorite values critized by Zhuangzi, 'The dignified people keep thinking of position and salary all day in case that crisis may fall. To treat one's own body in such a way, isn't it too negligent?'

Nowadays, the design trend of low carbon and sustainability accord with the design idea of Zhuangzi to some degree. The return of human nature in design ideas in this materialistic society is not only refers to the self-consciousness in the development of design culture, but also an invisible popularization of design morality. As Zhuangzi said, 'Small perplexity confuses the direction, big perplexity confuses the nature.' He also said that since the end of Zhou dynasty, all things or people in the society are changing their natures by outward things, and what people are pursuing for is nothing but material conditions, such status, position, fortune, in order to establish identity. As designers, they have the responsibility to design a product meeting people's demands on aesthetic value in its appearance as well as on its functions.

\section{Design thoughts: 'the use of useless use' and flexible innovation}

Contemporary design stresses more on the shift of the mode of design thinking, and the flexible innovation on design thoughts. For instance, product design had already transformed from single structure to diversification and multilayers, from single and specific product design domain to 'Big design' conception of systematic integrated planning. Traditionally, a product is material that integrated form, color, structure, materials, and it provides people with good interpersonal relationship, convenient tools, and comfortable working and living environment with safety and artistry. Now it also synthesizes many elements in systematic design, such as elements of economy, society, environment, ergonomics, psychology and aesthetics. Besides, flexible innovation can permeate through every steps of product design, including changing its original attribute and style, improving its quality, and making new service for customers. In general, only integrate flexible innovation with different kinds of creative concept, can we actually and effectively improve the product's added value and competitiveness.

\section{A. The 'use' in 'the useless use'}

In the article The happy excursion, Zhuangzi describes a story:

Huizi said to Zhuangzi, "The Prince of Wei gave me a seed of a large-sized kind of gourd. I planted it, and it bore a fruit as big as a five-bushel measure. Now had I used this for holding liquids, it would have been too heavy to lift; and had I cut it in half for ladles, the ladles would have been too flat for such purpose. Certainly, it was a huge thing, but I had no use for it and so broke it up." "It was rather you did not know how to use large things,” replied Zhuangzi, “......Now as to your five-bushel gourd, why did you not make a float of it, and float about over river and lake? And you complain of its being too flat for holding things! I fear your mind is stuffy inside.”

This story describes a conversation between Zhuangzi and Huizi to illustrate that they are differed in thoughts. Huizi insists in the concept of big and small, use and useless. He wants to make things useful, so he looks for the suitable conditions of the big gourd, but the results is that it become completely useless. However, Zhuangzi use a thing based on its attributes, so he is a man with great wisdom.

To put it simply, the above fable tells us the philosophy that usefulness and uselessness exist in relative terms. Based on his fixed mindset, Hui Shi believes that gourds can only be used to hold 
water. However, Zhuangzi uses the gourds in a different way, showing the magical effect and revealing the "usefulness of the uselessness".

According to Zhuangzi, everyone knows what usefulness is, but barely comprehends what usefulness of the uselessness means. Nothing is absolutely useless in the world and a different way of using things really counts. The value of same thing often varies for different people, or in different circumstances. Hui Shi is "unknown of the use of gourds whereas Zhuangzi maintains "usefulness of the uselessness", the two different ideas that are generated for some reasons that Shi Hui always sticks to convention and Zhuangzi manages to break the conventional practice. Actually, people often neglect the "usefulness" of useless things and magical use of the useful things.

\section{B. Adaptability and innovation}

From the point of view of innovation, adaptability and innovation do not mean that major changes must be made to the main attributes and structure of products. The problems they have solved seem to be trivial, but it is the adaptations that have weakened the consumption-led economy and have played a bigger role in consumers' choices.

Take the world-renowned watch brand Swatch as an example. Since Nicholas G. Hayek founded the Swatch Group on the basis of corporate restructuring in 1985, the Swatch has always been popular for its unique creativity and fashion elements. Its original series bracelet watches, in particular, have been favored by millions of young people all over the world. On top of the success in design, the Swatch has positioned it as the fashionable accessory, which have broken traditional core values in Swiss watch industry such as the expensiveness, durability and symbol of taste, and has also adopted the strategy of limited release with quality certificate. Given that, Swiss watches can be "possessed and collected by ordinary people". Furthermore, the watchmakers of the Swatch Group have replaced at least 91 parts that constitutes wristwatches with 51 parts, ultimately making plastic watches possible and price affordable. This example indicates that the adaptability in the creative process, sales sections, etc., may bring huge benefits to the company.

Alessi is a famous Italian domestic manufacturer. Its success can be attributed to a group of world-renowned designers, including Philippe Starck, Achille Castiglioni, and Michael Grave and some classical works they designed. Another key reason is that Alessi has reformed the way we look at household goods and transformed the basic practical products into innovative, colorful and ingenious ones for families. Products of Alessi are hailed as being "poetic and interesting” as the company pays great attention to the design emotion of products, including the design of returning to nature, the design with folk culture features, the design of using cartoons, and the design with exquisite craftsmanship.

The combination of adaptable innovation and emotional design is a perfect match. In the course of the industrial design, functionalists pursue the function between objects and people. They also stand for mass production, cubism and the application of modern materials, but oppose decoration. Later the trend of minimalism catches on and people begin to recognize the importance of the humanistic care of products. Emotional factors embodying in the product makes its appearance more diversified. Emotional design tightens the good emotional communication between people and products, making products humanized rather than function-oriented. Therefore, people shift attachment away from the products to products and brands all together. In addition to concept and technology, emotional design is a yet another good example of adaptable innovation. If the consumers' affection for the product surpasses the basic relationship between people and objects, and gradually develops into the emotional connection, consumers will faithfully accept the product and the brand for the long term.

\section{Conclusion:}

Aesthetic thoughts of Zhuangzi are extensive and profound. It is obvious that his thoughts and discourses are not exclusively composed for craftsmanship and design. However, when we read them, many views in their works are directly or indirectly on craftsmanship and creation. This demonstrates that in the age of Zhuangzi, craftsmanship and design influenced people's way of life 
and people begun to figure out the relationship between people and objects, people and the world. In this regard, thoughts of Zhuangzi have brought inspiration to our design.

Besides, Zhuangzi's aesthetics underscore concepts of the freedom of individual life, of "Fast of Heart” and "Sitting in Oblivion”, of "Void Quietness” and of “Observing Thing through Itself”, directly elevating the level of Chinese art and painting. It can also be said that his thoughts represent the spirit of art. Zhuangzi boasts graceful style and the rhetoric behind it is the enthusiasm, airiness, meditation and profound alertness and timeless wisdom behind it. It is this poetic treatment that makes Zhuangzi's thought "a wonderful poem” and a splendid intellectual and spiritual treasure.

\section{References}

[1] Ren Jiyue. History of Chinese Philosophy, Pre-Qin Dynasty[M]. Beijing: People's Publishing House, 1983: 379.

[2] Li Xiangfeng. The Collection and Annotation of Guanzi [M]. Beijing: Zhonghua Book Company, 2004: 626.

[3] Cao Chuji. A general Annotation on Zhuangzi. Beijing: Zhonghua Book Comapny, 1982.

[4] Zhang Mosheng. A new version of Annotation on Zhuangzi. Beijing: New World Press, 2007.

[5] Li Zehou Liu Gangji. History of Chinese Aesthetics. Anhui: Anhui Literature and Art Publishing House, 1999.

[6] Qi Zhixiang. The general history of Chinese aesthetics. Beijing: People's Publishing House,2008.

[7] Wang Shouzhi. History of World Modern Design. Beijing: China Youth Publishing Group, 2002. 